This item was submitted to Loughborough's Research Repository by the author.

Items in Figshare are protected by copyright, with all rights reserved, unless otherwise indicated.

\title{
Comparing the dynamic flow properties and compaction properties of pharmaceutical powder mixtures
}

PLEASE CITE THE PUBLISHED VERSION

https://doi.org/10.1002/ceat.201600651

PUBLISHER

(c) Wiley

VERSION

AM (Accepted Manuscript)

\section{PUBLISHER STATEMENT}

This work is made available according to the conditions of the Creative Commons Attribution-NonCommercialNoDerivatives 4.0 International (CC BY-NC-ND 4.0) licence. Full details of this licence are available at: https://creativecommons.org/licenses/by-nc-nd/4.0/

\section{LICENCE}

CC BY-NC-ND 4.0

\section{REPOSITORY RECORD}

Leaper, Mark C., Kashaf Ali, and Andrew J. Ingham. 2017. "Comparing the Dynamic Flow Properties and Compaction Properties of Pharmaceutical Powder Mixtures”. figshare. https://hdl.handle.net/2134/26620. 


\title{
Comparing the dynamic flow properties and compaction properties of pharmaceutical powder mixtures
}

\author{
Mark C. Leaper ${ }^{* 1}$, Kashaf Ali $^{2}$, Andrew J. Ingham ${ }^{3}$ \\ ${ }^{1}$ Department of Chemical Engineering, Loughborough University, Loughborough, \\ Leicestershire, LE11 3TU, UK. \\ ${ }^{2}$ School of Pharmacy, Aston University, Birmingham, B4 7ET, UK. \\ ${ }^{3}$ AJI Technology, Keighley, W. Yorkshire, UK.
}

\begin{abstract}
The dynamic flow properties and compaction characteristics of mannitol and mannitol-sodium carbonate mixtures ( $80 / 20,70 / 30$ and $60 / 40$ by mass) were measured using a Freeman FT4 powder rheometer. The results showed that the mixtures containing up to $30 \%$ sodium carbonate had better flow properties and improved compaction characteristics when compared with mannitol alone. The study demonstrated the feasibility of combining a more expensive pharmaceutical excipient with a cheaper ingredient, without compromising desired powder characteristics. It may also provide a useful method for assessing the suitability of new formulations for use as direct compression bases, as part of a wider range of powder flow tests.
\end{abstract}

\section{Introduction}

The use of mannitol in pharmaceutical formulations has increased recently, as it is stable, inert and has a minimal allergy effect [1]. However, it is more expensive than other diluent powders and using it in combination with other cheaper ingredients such as sodium carbonate may reduce costs. This study will examine the technical feasibility of such an approach by measuring the powder flow properties of mixtures of the materials.

The starting point for assessing the flow characteristics of a powder has traditionally been the Jenike shear cell [2-3], and many modern techniques are still based on the principles behind this tester [3-5]. However, whilst good data from this method is excellent for designing silos and provides a firm basis for assessing behaviour during long-term storage, it does not always give an indication of powder behaviour in dynamic processes such as the filling and operation of tablet machines.

Analysing the behaviour of powders under dynamic conditions is challenging and two approaches have dominated this area. The first approach used a rotating drum to produce avalanches in the powder [6-8]; analysis of the cyclical motion of a particle or group of particles determines the relationships between particle characteristics and the rotational frequency.

A second approach to analysing dynamic powder flow is to use a powder rheometer with a twisted blade that passes through the powder with a predetermined path, measuring the resistance encountered and the energy required to make the powder flow around the blade. The most recent machine to use this approach is the Freeman FT4 [9-10].

The compaction curve of a powder system can also provide useful information on its tabletforming capabilities, examining the mechanisms of powder compaction, through a combination of particle re-arrangement, breakage and plastic deformation [11]. It has also allowed relationships between the tensile strength of the compact and the strength of the particles themselves to be formulated [12-13]. The FT4 system is capable of performing dynamic, compaction and shear cell tests and will be used to compare the dynamic flow and compaction characteristics of mannitol-sodium carbonate mixtures. It will examine whether 
adding a cheap inert powder to mannitol could improve powder flow and compressibility and establish any trends that would link compaction characteristics to dynamic flow properties.

\section{$2 \quad$ Material and Methods}

\section{$2.1 \quad$ Test Materials}

The two materials tested were mannitol and sodium carbonate monohydrate, both obtained from Fisher Scientific, UK. The cumulative particle size distributions for these are shown in Figure 1; these were obtained using sieves.

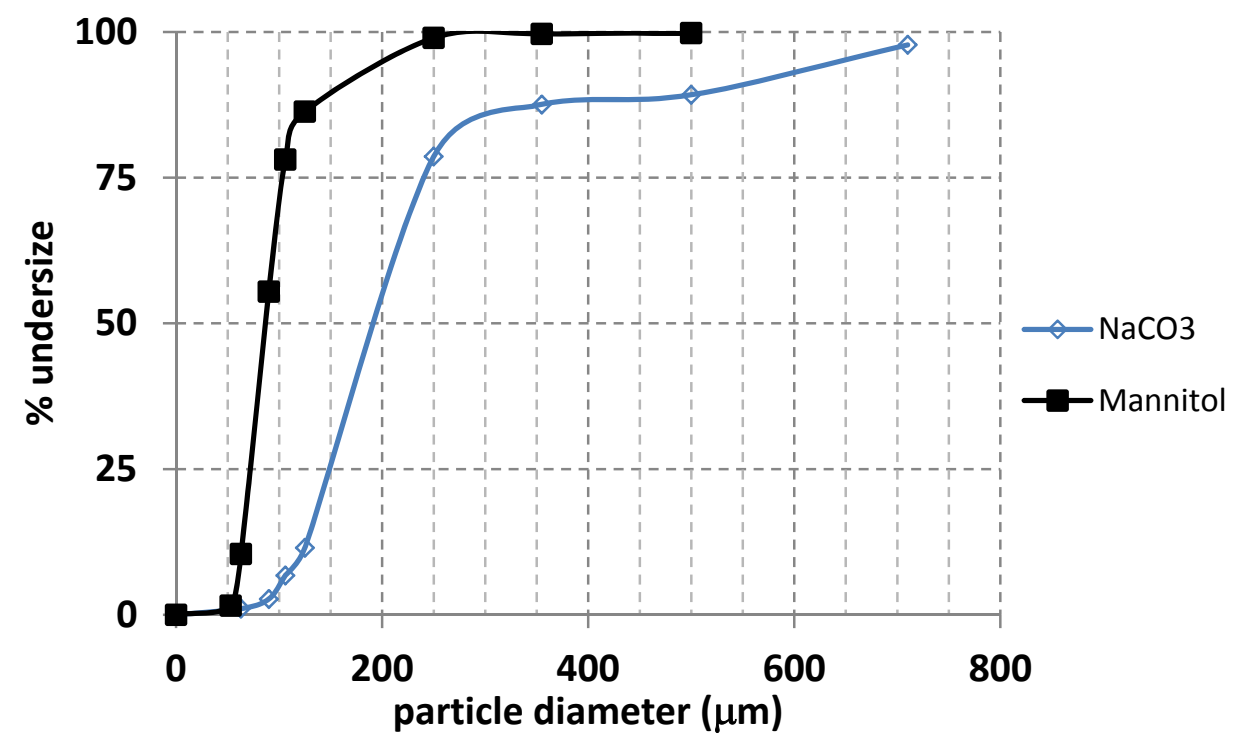

Figure 1: Cumulative undersize distribution of test samples Sodium Carbonate and Mannitol, obtained from sieving.

The powders were stored in sealed containers at $20^{\circ} \mathrm{C}$ prior to use. The sample sizes for use in the tester were approximately $50 \mathrm{~g}$ and were blended individually prior to each test. The test mixtures were $80: 20,70: 30$ and $60: 40$ of mannitol to sodium carbonate by mass respectively and were mixed using a manual tumbling method to avoid any particle degradation. The tests were conducted under normal ambient conditions of $20^{\circ} \mathrm{C}$ and $50 \%$ $\mathrm{RH}$. The mixtures were also characterised using a tapping volumeter, which compared the bulk density of each mixture before and after 200 tapping cycles; this allowed the Hausner ratio, the bulk density after the test divided by the bulk density before, to be determined. 


\subsection{The Freeman FT4 Compaction Test}

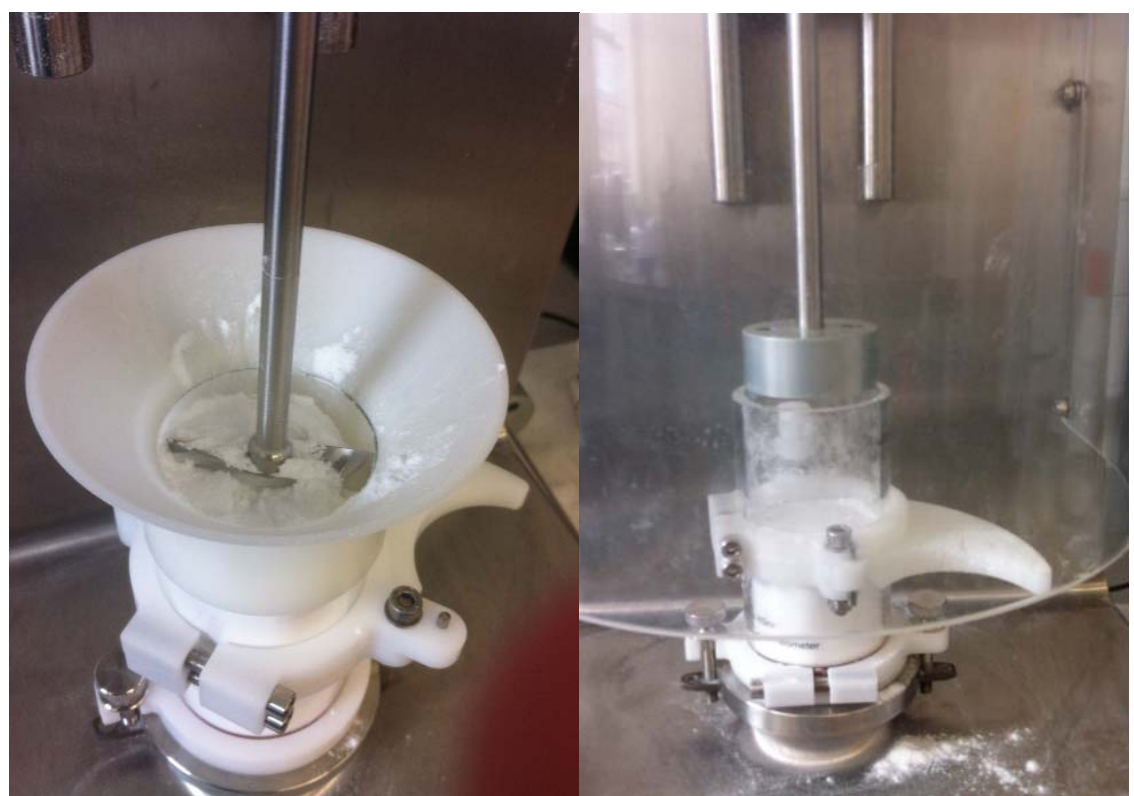

Figure 2: Experimental configurations for (a) preconditioning a powder and (b) compaction using the FT4.

Each sample in the compaction test was first pre-conditioned with a single upwards and downwards cycle using the blade from the dynamic tester, as shown in Figure 2(a) and described in previous studies [9-10]. A vented piston was then used to compact the powder as shown in Figure 2(b). The load was progressively increased in small increments up to $15 \mathrm{kPa}$ and the percentage change in powder volume was recorded at each new load. The diameter of the compacted system was $48 \mathrm{~mm}$.

\subsection{Dynamic Test}

The dynamic flow tester works on the principle of using a rotating blade described in Figure 2(a) to determine the energy required to deform a conditioned bed of powder of diameter $48 \mathrm{~mm}$, as explained by Freeman [9]. The energy is obtained by integrating a Force-Distance curve based on 11 repeated downwards and upwards cycles of the blade through a preconsolidated bed. The first eight tests are performed with a constant blade tip speed of 100 $\mathrm{mm} \mathrm{s}^{-1}$; this is then progressively reduced to 70,40 and $10 \mathrm{~mm} \mathrm{~s}^{-1}$ on tests 9 to 11 respectively. The repeated testing enables the powder to be analysed for its tendency to flow under dynamic conditions and also takes account of any degradation of particle during testing. Parameters determined by the test include the following:

Basic Flow Energy (BFE) - this is the energy required to move the blade downwards in cycle 7 , by which time a stable, consistent flow pattern will have been established within the powder. It is useful for comparative and qualitative assessment of powder flow, but incorporates the effect of several mechanisms.

Specific Energy (SE) - this is the average energy required to move the blade upwards in cycles 6 and 7. This is useful for assessing flow in low-stress conditions, such as tablet die filling. It is mostly affected by cohesion and not compressibility. Values of SE below 5 indicate a free-flowing powder, with an SE above 10 indicating a cohesive material. Flow Rate Index (FRI) - this is the flow energy during the downward cycle 11 divided by cycle 8 . This assesses the effect of reducing the blade rotational speed.

Stability Index (SI) - this is the flow energy of cycle 7 divided by cycle 1 and indicates if the particle size distribution has been affected by the repeated testing. A Stability Index significantly higher than 1 indicates mechanisms attributed to an increase in particle size. An 
overall decrease in particle size is indicated by SI being significantly less than 1 and is usually attributed to powder caking before the test.

\subsection{Freeman FT4 Shear Cell Test}

The FT4 rotational shear cell shown in Figure 3 works on the principle that the vaned section causes the top layer of pre-consolidated powder to shear, whilst the bottom layer remains stationary; this enables a Mohr circle to be obtained for the consolidating stress, providing values for the principle consolidating stress and unconfined yield stress. The consolidating stresses used by the system were 3, 6, 9 and $15 \mathrm{kPa}$ and these were applied momentarily. Previous studies have validated the FT4 shear tester using standard CRM116 Limestone, with the flow function data obtained in agreement with the original Jenike system [8].

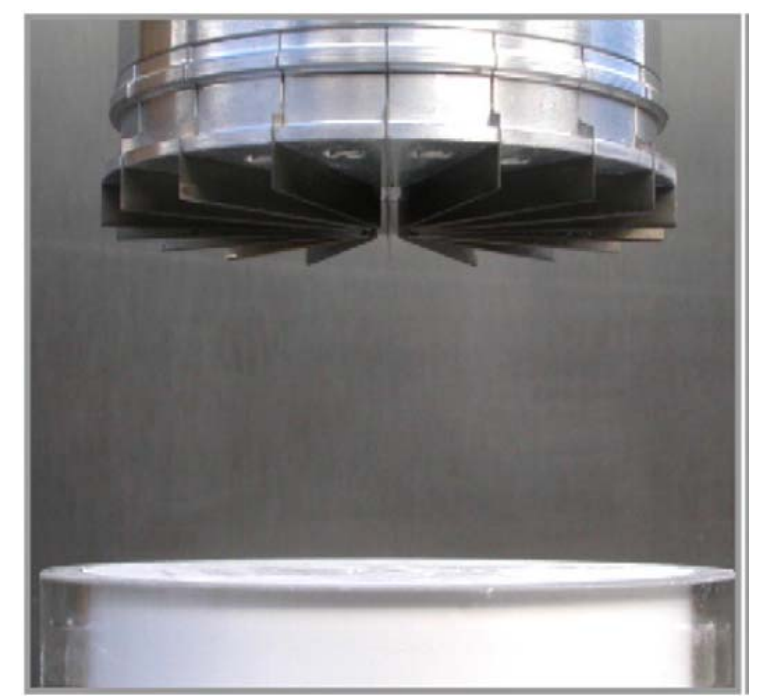

\section{Figure 3: The FT4 shear cell}

As with the compaction test, the sample was first pre-conditioned using the dynamic blade. The vented piston used in the compaction test was then use to pre-consolidate the powder under a controlled normal load $(3,6,9$ or $15 \mathrm{kPa})$. The split cell sample was pre-sheared using the apparatus in Figure 3 . The main experiment then consisted of the shear apparatus in Figure 3 measuring the shear stress required to cause failure under a normal load to produce a yield locus. 


\subsection{Compaction Test}

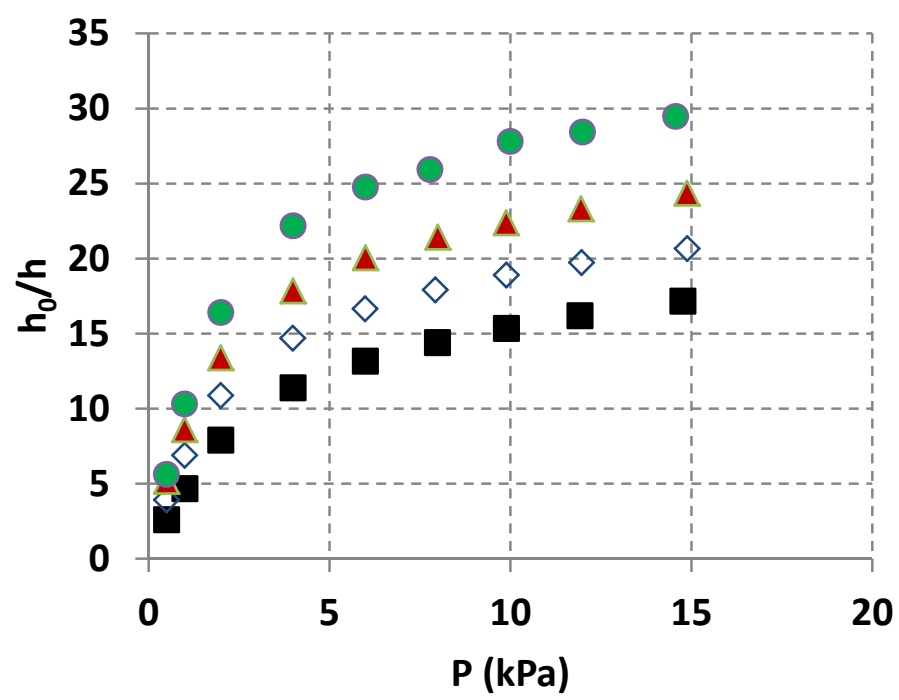

mannitol

$\diamond 80 / 20$ mixture

$\Delta 70 / 30$ mixture

$60 / 40$ mixture

Figure 4: $\quad$ Bed height variations effect on compaction force ( $\mathrm{kPa})$ for Mannitol and Sodium Carbonate mixtures.

Figure 4 shows a plot of compacting load $P$ in $\mathrm{kPa}$ against the ratio of initial bed height $h_{0}$ to compacted bed height $h$ for the mannitol and test mixtures. This was found to follow the relationship for confined compaction of powders suggested by Adams et al. [12] at high values of $h_{0} / h$ :

$$
\ln \left(\frac{\mathrm{h}_{0}}{\mathrm{~h}}\right)=\frac{1}{\alpha} \ln \mathrm{P}-\frac{\mathrm{C}}{\alpha}
$$

Figure 5 confirmed that this correlation is valid for these systems, with the gradient, intercept and $R^{2}$ values also summarised in Table 1.

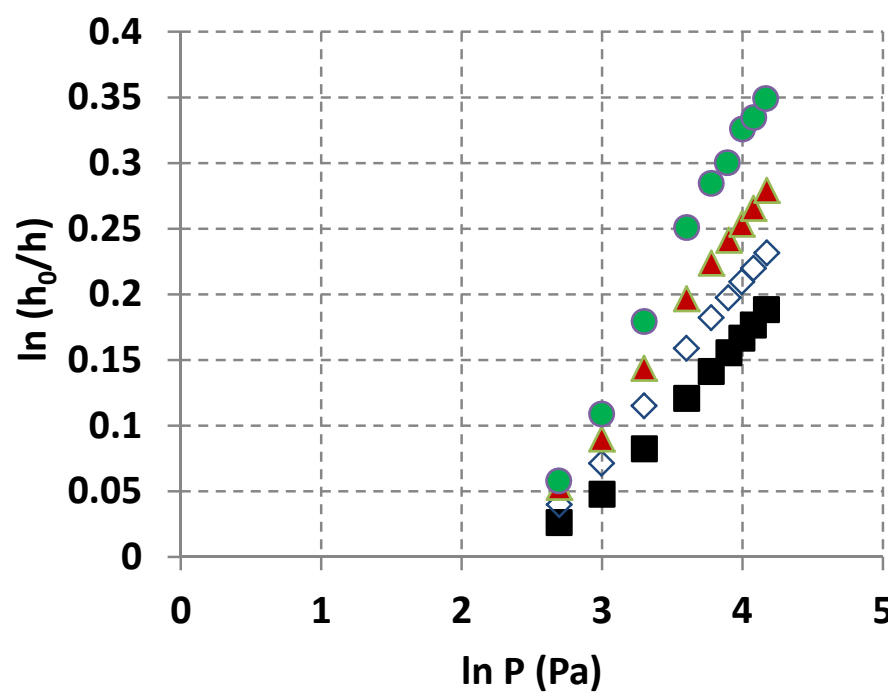

mannitol

$\diamond 80 / 20$ mixture

$\Delta 70 / 30$ mixture

$60 / 40$ mixture

Figure 5: Natural log-log plot of data in Figure 3, confirming the compaction relationship suggested by Adams et al. [12]. 
Adams et al. [12] defined $\alpha$ as the coefficient of friction in the coulomb model of powder failure:

$$
\tau=\tau_{0}+\alpha \mathrm{P}
$$

where $\tau$ is the shear failure strength and $\tau_{0}$ the cohesion. The data suggest that the compaction characteristics of mannitol can be influenced significantly by adding sodium carbonate, with an increase in the coefficient of friction, $\alpha$. The cohesion, $\tau_{0}$, can also be obtained using the relationship:

$$
\begin{aligned}
& C=\ln \left(\frac{\tau_{0}}{\alpha}\right) \\
& \tau_{0}=\alpha \mathrm{e}^{\mathrm{C}}
\end{aligned}
$$

\begin{tabular}{|c|c|c|c|c|c|c|}
\hline $\begin{array}{c}\text { Test sample } \\
\begin{array}{c}\text { Mannitol: } \mathrm{Na}_{2} \mathbf{C O}_{3} \\
\text { (w/w) }\end{array}\end{array}$ & $\mathbf{1 / \alpha}$ & $-\mathbf{C l} \boldsymbol{\alpha}$ & $\mathbf{R}^{2}$ & $\boldsymbol{\alpha}$ & $\mathbf{C}$ & $\tau_{\mathbf{0}}(\mathbf{P a})$ \\
\hline mannitol & 0.1133 & -0.2862 & 0.9955 & 8.8 & 2.52 & 110 \\
\hline $80 / 20$ & 0.133 & -0.3219 & 0.9986 & 7.5 & 2.42 & 85 \\
\hline $70 / 30$ & 0.1574 & -0.3746 & 0.9978 & 6.3 & 2.38 & 69 \\
\hline $60 / 40$ & 0.2041 & -0.4934 & 0.9965 & 4.9 & 2.41 & 55 \\
\hline
\end{tabular}

Table 1: $\quad$ A summary of parameters obtained from the data in Figure 5.

Table 1 shows that increasing the proportion of sodium carbonate decreases the cohesion and of the powder under the same range of compressive loads, whilst increasing the compressibility.

\subsection{Dynamic Blade Test}

The dynamic blade test was performed on the mannitol and the mannitol-sodium carbonate mixtures, with the flow energy for each successive test shown in Figure 6.

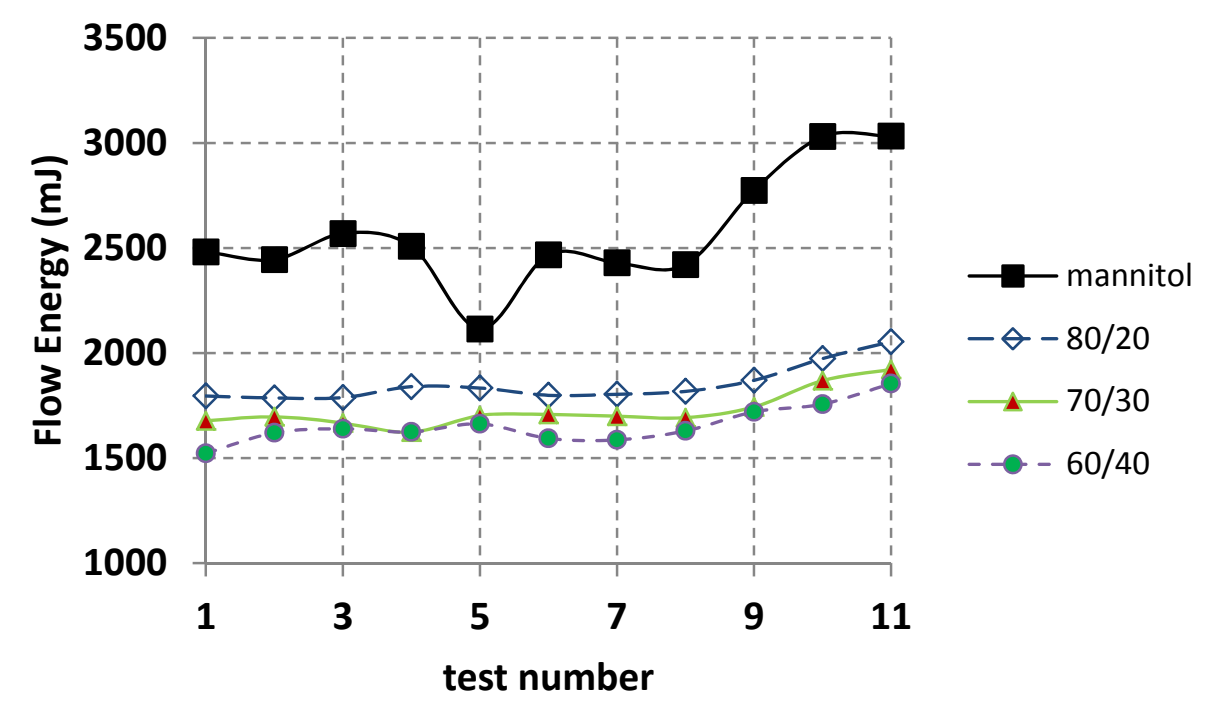


Figure 6: The dynamic test data obtained for the mannitol and mannitol-sodium carbonate mixtures.

Table 2 compares the Basic Flow Energy (BFE), Specific Energy (SE), Flow Rate Index (FRI) and Stability Index (SI) obtained from the FT4 data in Figure 5 with the Hausner ratio $\mathrm{H}$ obtained from volumeter readings.

\begin{tabular}{|c|c|c|c|c|c|}
\hline $\begin{array}{c}\text { Test sample } \\
\text { Mannitol:Na } \mathbf{C} \\
\mathbf{O}_{\mathbf{3}} \text { (w/w) }\end{array}$ & BFE, $\mathbf{m J}$ & SE, $\mathbf{~} \mathbf{J} / \mathbf{g}$ & FRI & SI & H \\
\hline mannitol & 2430 & 12.12 & 1.25 & 0.98 & 1.32 \\
\hline $\mathbf{8 0 / 2 0}$ & 1804 & 10.30 & 1.13 & 1.00 & 1.20 \\
\hline $\mathbf{7 0 / 3 0}$ & 1700 & 9.54 & 1.14 & 1.01 & 1.18 \\
\hline $\mathbf{6 0 / 4 0}$ & 1587 & 9.07 & 1.14 & 1.04 & 1.31 \\
\hline
\end{tabular}

Table 2: $\quad$ Basic Flow Energy (BFE), Specific Energy (SE), Flow Rate Index (FRI) and Stability Index (SI) obtained from the FT4 dynamic blade test compared with the Hausner Ratio $(\mathbf{H})$.

The stability index was close to 1 , ruling out the possibility that the blade had changed the particle size of the powder through agglomeration, degradation or segregation. It also showed that there was no significant agglomeration when the two powders were mixed. The energy required to displace the powder decreased as the proportion of sodium carbonate increased, with a clear difference between pure mannitol and the mixtures. This was particularly relevant in the values of Specific Energy (SE), which indicated the flow characteristics in a dynamic situation such as filling a tablet machine; these values followed the same trend as the measurement of cohesion data from the compaction.

\subsection{Shear Cell}

The mannitol and mixtures were tested using the FT4 shear cell, with a yield loci shown in Figure 7 for mannitol at a consolidating stress of $15 \mathrm{kPa}$. From the Mohr circles, the unconfined yield stress $\sigma_{C}$ and principle consolidating stress $\sigma_{1}$ were obtained, as well as the cohesion. Table 3 summarises the cohesion values for the samples, indicating an increase with consolidating stress for the same mixture.

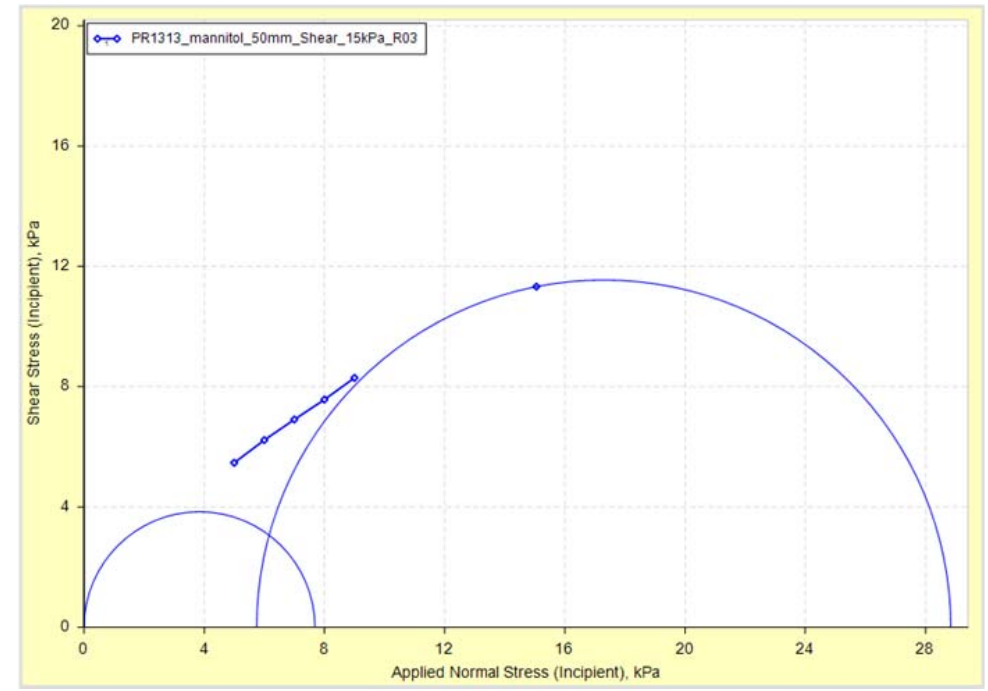

Figure 7: An example of the yield loci obtained - mannitol with a consolidating load of $15 \mathrm{kPa}$. 


\begin{tabular}{|c|c|c|c|c|}
\hline Test sample & \multicolumn{4}{|c|}{ Cohesion at } \\
\hline $\begin{array}{c}\text { Mannitol: } \mathrm{Na}_{2} \mathrm{CO}_{3} \\
(\mathrm{w} / \mathrm{w})\end{array}$ & $3 \mathrm{kPa}$ & $6 \mathrm{kPa}$ & $9 \mathrm{kPa}$ & $15 \mathrm{kPa}$ \\
\hline $100 / 0$ & $0.84 \mathrm{kPa}$ & $0.98 \mathrm{kPa}$ & $1.19 \mathrm{kPa}$ & $1.89 \mathrm{kPa}$ \\
\hline $80 / 20$ & $0.62 \mathrm{kPa}$ & $0.83 \mathrm{kPa}$ & $1.3 \mathrm{kPa}$ & $1.50 \mathrm{kPa}$ \\
\hline $70 / 30$ & $0.9 \mathrm{kPa}$ & $0.97 \mathrm{kPa}$ & $1.24 \mathrm{kPa}$ & $1.44 \mathrm{kPa}$ \\
\hline $60 / 40$ & $0.74 \mathrm{kPa}$ & $1.02 \mathrm{kPa}$ & $1.17 \mathrm{kPa}$ & $1.47 \mathrm{kPa}$ \\
\hline
\end{tabular}

Table 3: $\quad$ Cohesion values obtained from Mohr circles of mannitol and mannitolsodium carbonate mixtures constructed from FT4 shear measurements.

Figure 8 is a plot of unconfined yield stress $\sigma_{\mathrm{C}}$ vs consolidating stress $\sigma_{1}$ for the mannitol and mannitol-sodium carbonate mixtures, obtained from shear tests at $3,6,9$ and $15 \mathrm{kPa}$; it shows how mixing the sodium carbonate with the mannitol has little effect on the flow function of the powder, with all mixtures giving a flowability index of around 5 . This corresponds to a system that flows quite well but is on the boundary of being cohesive, as described by Leturia et al. [10].

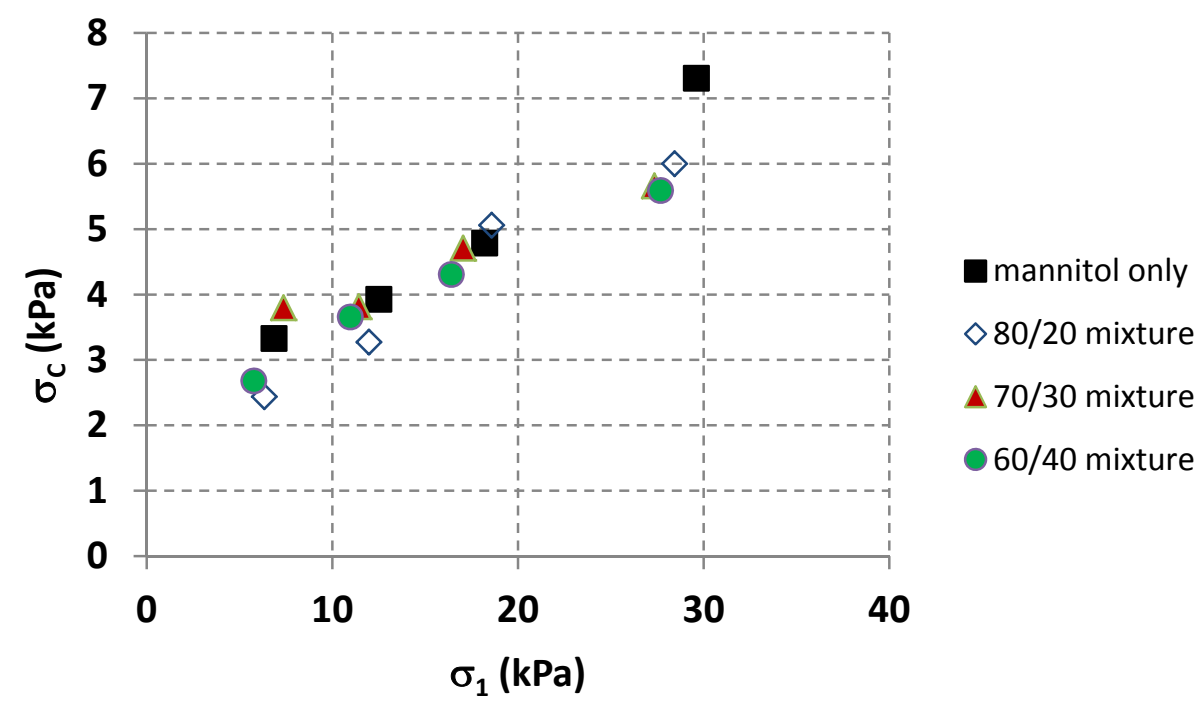

Figure 8: $\quad$ Plot of unconfined yield stress $\sigma_{\mathrm{c}}$ vs principle consolidating stress $\sigma_{1}$ for the mannitol and mannitol-sodium carbonate mixtures.

\subsection{Comparison of the results obtained and their physical meaning}

Mannitol on its own had a Specific Energy of $12 \mathrm{~mJ} / \mathrm{g}$, which indicated cohesive behaviour, and this was confirmed in the compaction test and Hausner ratio. The coefficient of friction obtained by the compaction test significantly reduced with increasing sodium carbonate content, contributing to a reduction in the cohesion and the Specific Energy. However, The Hausner ratio increased again significantly with the 60/40 mixture, indicating that the orientation and rearrangement of particles also contributed to the open structure in this system. The combination which was most suitable for tablet manufacture was the 70/30 mixture, which had lower cohesion (69 $\mathrm{Pa}$ as opposed to $110 \mathrm{~Pa}$ ) and better compressibility 
than mannitol alone, but did not have the high aeration tendencies of the $60 / 40$ mixture. However, the differences between the different mixtures would not have been resolved by the use of a shear cell alone.

\section{Conclusions}

The compaction characteristics and flow properties shown by mannitol could be improved by adding sodium carbonate. The Specific Energy of powder mixtures obtained from the Freeman FT4 showed similar trends to the cohesiveness obtained from the compaction studies, with an increase in sodium carbonate content reducing both values. However, the Hausner ratio of the 60/40 mannitol-sodium carbonate mixture was the same as for mannitol, indicating that the most suitable composition for tablet manufacturing is the 70/30 mixture. These results show that this method could be used in preliminary studies to develop tablet formulations, revealing significant differences in behaviour that could not be clearly resolved using shear cell tests.

\section{Acknowledgements}

The authors are grateful to McBride, Barrow in Furness, Cumbria, UK, for communications throughout the study.

\section{Funding}

This research did not receive any specific grant from funding agencies in the public, commercial or not for profit sectors.

\section{References}

[1] H.L. Ohrem, E. Schornik, A. Kalivoda, R. Ognibene, R., Pharmaceutical Development and Technology, 2014, 19(3), 257-262.

[2] A.W. Jenike, Gravity flow of bulk solids. Utah University Engineering Experiment Station 123, 1962.

[3] J. Schwedes, D. Schultz, Powder Technology, 1990, 61, 59-68.

[4] J. Schwedes, Granular Matter 2003, 5, 1-43.

[5] R.J. Berry, M.S.A. Bradley, R.G. McGregor, Proceedings of the IMechE (Part E) Journal of Process Mechanical Engineering 2015, 229 (3), 215-230.

[6] Y.L. Ding, R.N. Forster, J.P.K Seville, D.J. Parker, Powder Technology, 2002, 124, 1827.

[7] A.W. Alexander, B. Chaudhuri, A. Faqih, F.J. Muzzio, C. Davies, M.S. Tomassone, Powder Technology, 2006, 164, 13-21.

[8] V. Jaggi, M.C. Leaper, A.J. Ingham, Drying Technology, 2016, 34(6), 723-728.

[9] R. Freeman, Powder Technology 2007, 174, 25-33.

[10] M. Leturia, M. Benali, S. Lagarde, I. Ronga, K. Saleh, Powder Technology 2014, 253, 406-423.

[11] M.C. Leaper, V. Leach, P.M. Taylor, D.C. Prime, Drying Technology, 2013, 31(7), 769774.

[12] M.J. Adams, M.A. Mullier, J.P.K. Seville, Powder Technology, 1994, 78, 5-13.

[13] S.F. Yap, M.J. Adams, J.P.K Seville, Z. Zhang, China Particuology 2006, 4 (1), 35-40. 